\title{
AN INVESTIGATION INTO THE EFFECTS OF PROGRAMMING WORKSHOP EXPERIENCES ON PARENTS' CONCERNS ABOUT PROGRAMMING EDUCATION IN ELEMENTARY SCHOOL
}

\author{
Yukiko Maruyama \\ Tokai University, Hiratsuka Kanagawa, Japan
}

\begin{abstract}
To investigate the effects that experiences in programming have on parents' concerns about programming education in elementary schools, a survey was carried out before and after parent-children workshops. Participation in the programming workshops seemed to promote parents' understanding of programming, boost their expectations, and decrease their anxieties about introducing programming education to primary schools. Moreover, attitudes and confidence in supporting children at home were improved through participation in the workshop. Since the number of participants in this study was limited, it is necessary to carry out the survey with more participants in the future, followed by detailed analysis.
\end{abstract}

\section{KEYWORDS}

Programming Education, Elementary School, Parents' Concerns, Computational Thinking, Programming Workshop

\section{INTRODUCTION}

There have been widespread attempts to introduce computational thinking to elementary/secondary or K-12 education (Barr and Stephenson 2011, Grover and Pea 2013). The term "computational thinking" was first used by Papert (1993), and was popularized by Wing (2006). According to Wing, "“Computational thinking' involves solving problems, designing systems, and understanding human behavior, by drawing on concepts that are fundamental to computer science." (p. 33). Additionally, she stated that computational thinking is a fundamental skill for everyone and that it should be added to every child's analytical ability. The article caught the attention of many education researchers and educators, and many research studies related to computational thinking in K-12 have since been carried out. In the United Kingdom, a new subject, "computing," was introduced to primary and secondary schools. In the primary teachers' guide for this subject, the importance of computational thinking is repeatedly stated.

As computational thinking increasingly draws attention, programming education is also receiving attention as one of the ways of teaching computational thinking. Lye and Koh (2014) state that "[p]rogramming is more than just coding; for, it exposes students to computational thinking which involves problem-solving using computer science concepts, and is useful in their daily lives" (p. 51). In Japan, the central council for education in the Ministry of Education, Culture, Sports, Science, and Technology submitted a report that mentioned the introduction of programming education to elementary schools. Another council report said that programming education in elementary schools should not aim to teach students how to code, but rather to foster students' programming thinking (translated by author). Programming thinking is considered to be a concept similar to computational thinking, and is also considered to be a part of computational thinking. However, the aim of programming education has not infiltrated the public adequately. Misconceptions and anxieties concerning programming education seem to have begun spreading among parents. Parents play a very important role in elementary education, and their attitudes toward education have considerable influence on children's attitudes. Indeed, some researchers have investigated parent-child collaboration in robotics education (Cuellar et al. 2013, Roque et al. 2016) and in learning programming (Lin and Liu 2012, Hart 2010). Parents' misconceptions and anxieties related to programming 
education could become obstacles to their involvement in children's learning. It is therefore important to know parents' concerns about programming education. Moreover, it is necessary to encourage parents' involvement in their children's programming education. This study aims to suggest a support system for parents to get them involved in programming education in elementary schools. This paper provides the results of a preliminary investigation into the influence of participation in a programming workshop for children and parents on changes in parents' concerns about programming education in elementary schools.

\section{RESEARCH STUDIES ON PARENTS' ROLE IN EDUCATION INVOLVING NEW TECHNOLOGY}

As mentioned above, parents' attitudes toward education have considerable influence on children's attitudes.

Hart (2010) carried out a computer science based workshop that targeted fourth through sixth graders, mainly female students, and their parents. Participants took part in an attitudinal survey during the first and last session of the workshop. The results of this survey show their perceptions of general computer use, the potential for a career as a computer scientist, and that perceived differences in ability based on gender became positive during the last session. Moreover, much of the feedback from parents was positive.

Lin and Liu (2012) observed three parent-child pairs in a computer camp used MSWLogo. They found that parent-child collaboration during programming naturally fell into a special form of "pair programming" and that children wrote programs in a more systematic and disciplined manner. Moreover, they reported that the programs produced by these participants were relatively more compact, well-structured, and error-free.

Cuellar et al. (2013) conducted a robotics education workshop in which parents and children interacted by experimenting with concepts of robotics and developing problem solving skills. They expected students to become more interested in technology and their parents to encourage them toward engineering and science majors. As a result, they observed enhanced teamwork and interaction as well as a positive attitude towards the initiative over the course of the workshop.

Thus, parents' involvement in education significantly impacts children's attitudes and outcomes. However, it seems that some parents have low confidence in their involvement in education, especially regarding new technology.

Feng et al. (2011) regard parents as important influencers in children's decision to attend a robotics course and the use of educational robots among children. Therefore, they investigated parents' perception of edutainment products including programmable bricks. They sent questionnaires to 55 parents and received 26 valid questionnaires. Questionnaires included questions about the usefulness of programmable bricks, and the respondent's confidence in teaching programmable bricks. The results showed that parents thought that programmable bricks were useful for their children, but they were not confident in using them to teach their children. Taking this into account, Feng et al. alluded to customized courses for both parents and children; and means of improving parents' confidence in teaching children for future research.

Lin et al. (2012) investigated parents' perceptions regarding educational robots. Results of responses to the self-report questionnaires from 29 parents indicated that parents had a positive attitude toward educational robots and considered learning about educational robots to be beneficial for children. Additionally, they found that parents have little confidence in using educational robots to teach or to play with their children. Therefore, they suggested that it was crucial to train or teach parents about educational robots.

As mentioned in these two research studies, participation in educational workshops could be one of the promising ways of improving parents' attitudes and confidence.

Roque et al. (2016) state that social support from parents could be essential to engage children in creative opportunities regarding computing; however, parents whose background in computing is limited are often unsure of the roles they can play. To develop such parents' support they suggest offering them a chance to gain first-hand experience in creative computing. Therefore, they examined the experiences of parents' participation in a community-based program where families design and invent together using creative technologies. Through case analyses of three parent-children groups, they illustrated how parents' participation in design-based activities with their children enabled and supported the roles that they played in the program. 
There are some research studies on the impact that parents' participation in parent-child workshops have on their attitudes, but they are not sufficient. In these studies, the numbers of participants were small. And there are very few studies focused on changes in parents' concerns. This paper provides the results of a preliminary investigation into the influence of participation in a programming workshop for children and parents on changes in parents' concerns about programming education in elementary schools.

\section{METHOD}

The survey for this study was carried out in programming workshops for children and their parents, organized by the author.

\subsection{Programming Workshops}

Three types of programming workshops took place in August, 2018. Participants were recruited via brochures distributed through seven local elementary schools in Kanagawa, which is near Tokyo. Participants required to attend the workshops were a group of children with their parents or guardians. Workshops were held 13 times in nine days. Participants took part in one of them. Each workshop took two hours.

In each workshop, there was one instructor (author) and one assistant (university student). At the beginning of each workshop, a short lecture about computer programming was given, and then participants carried out workshop activities. A total of 83 groups took part in the workshop. Of these groups, five included two children, and one group included both parents.

\subsubsection{Programing Workshop 1}

Cubetto (Primo Toys https://www.primotoys.com/) was used in workshop 1. Cubetto is an educational and screenless coding toy for children aged three to six years. Users can make a program that controls cubetto's movements using coding blocks by placing them in a control board. The workshop targeted first and second grade students. A total of 16 groups took part in the workshop in four days. In the workshop, each group used one set of cubetto.

\subsubsection{Programing Workshop 2}

A toy robot BB-8 $8^{\mathrm{TM}}$ App-Enabled Droid ${ }^{\mathrm{TM}}$ (Sphero https://www.sphero.com/) and visual programming language SpheroEdu (https://edu.sphero.com/) were used in workshop 2. The workshop targeted third to sixth grade students. A total of 37 groups took part in the workshop in four days. In the workshop, each group used one BB-8.

\subsubsection{Programing Workshop 3}

Visual programming language Scratch (The Lifelong Kindergarten Group at the MIT Media Labhttps://scratch.mit.edu/)was used in workshop 3. The workshop targeted first to sixth grade students. A total of 30 groups took part in the workshop in five days. In the workshop, parents and children used a computer by themselves.

\subsection{Investigation}

\subsubsection{Questionnaires}

The investigation was carried out using questionnaires that had the following sections: 1) demographics of participants and their children (only in the questionnaire administered before the workshop), 2) participants' interests in programming education, 3) attitudes toward programming education in elementary schools, 4) expectations of introducing programming education to elementary schools, 5) anxieties regarding the introduction of programming education, 6) attitudes toward and confidence in supporting children's programming education at home, and 7) participants' experiences in computer usage (only in the 
questionnaire administered before the workshop). There were other questions that sought responses from children, but the results of responses to these questions have not been included in this paper.

\section{Expectations of Introducing Programming Education to Elementary Schools}

Parents who are not familiar with computer programming think that outcomes of programming education are merely related to computers. So, they expect children to get familiar with computers or acquire skills or knowledge related to computers.

On the other hand, Resnick (2011), who is known as the central researcher in a research group developing the Scratch, mentioned that as member of the Scratch community become more fluent with digital media, they develop an important array of "fluency skills" in particular thinking creatively, reasoning systematically and working collaboratively. He also stated, "These skills are essential for full participation and success in today's workplace, not only for computer programmers but for marketing managers, journalists, graphics designers, and most other occupations." Moreover, Yamamoto et al. (2016) examined the educational significance of programming education in elementary secondary education by reviewing previous research studies. As a result, they suggested that the educational significance and learning effect of programming education are to obtain skills such as inquiring skills, algorithmic and logical thinking skills, comprehension skills, communication skills, collaborative skills, and informational perspectives and ways of thinking. Considering the above, twenty-three items were created (table 8). These items are categorized into five categories including P: related programming (item 17), C: related computer and knowledge of computer and ICT (item 1, 2, 5, 6, 13, 14, 15, 16 and 18), J: related future job (item 4 and 7), S: related other subjects (item 19 and 21), and G: general skills (item 3, 8, 9, 10, 11, 12, 20 and 22).

\section{Anxieties Regarding the Introduction of Programming Education}

With regard to anxieties, two research studies related to English education in elementary school (Morita 2011, Makino 2008) were referenced while creating the items (table 8). The reasons for this reference are as follows. 1) There are only a few research studies related to programming education in elementary schools focusing on parents' concerns. 2) English education will be introduced into Japanese elementary schools as a subject from 2020. Compared to programming education, English education in elementary school appears to receive more attention from researchers; therefore, there are several insightful studies on this matter. It is apparent that useful suggestions for research on programming education can be gained from these studies.

The aim of the study by Morita (2011) was to establish a learning environment for English education at home. They stated that it was necessary to know parents' concerns regarding English education in order to establish the appropriate environment. Therefore, they studiously considered items to incorporate in a questionnaire to investigate parents' concerns, and chose items regarding parents' anxieties about English education.

Makino (2008) carried out a survey on parents' concerns about English education in elementary school. The results of the survey showed that parents were anxious about the contents and policies of education, and about teachers.

\subsubsection{Respondents}

Participants in workshops were handed two questionnaires at the reception and were asked to fill them before and after the workshops respectively; this was voluntary. Sixty-six valid responses were obtained. Of the 66 respondents in the survey, 51 were mothers and 15 were fathers of elementary school children. The average age of respondents was 41.9. The ages of respondents and the school years of their children are shown in tables 1 and 2, respectively.

Table 1. Ages of Participants

\begin{tabular}{r|r}
\hline Age & Freq. \\
\hline \hline-39 & 17 \\
\hline $40-44$ & 34 \\
\hline $45-49$ & 11 \\
\hline $50-$ & 4 \\
\hline
\end{tabular}

Table 2. School Years of Participants' Children

\begin{tabular}{|c|c|}
\hline School year & Freq. \\
\hline 1 & 7 \\
\hline 2 & 9 \\
\hline 3 & 11 \\
\hline 4 & 17 \\
\hline 5 & 12 \\
\hline 6 & 11 \\
\hline
\end{tabular}




\section{RESULTS AND DISCUSSION}

\subsection{Experiences of Computer Usage and Interests in and Attitudes toward Computer Education}

As shown in table 3 and 4, more than two thirds of respondents use computers in work or daily life. Table 5 shows respondents' self-evaluations of their computer skills. About one third of them answered "capable," but about $60 \%$ of them answered "not very skilled" or "not skilled at all." It seems that respondents in this study were relatively familiar with computers but not very skilled.

Table 3. Experience of using computers at work

\begin{tabular}{l|r}
\hline Responses & $\begin{array}{l}\text { Freq. } \\
(\%)\end{array}$ \\
\hline \hline I have a computer-related job & $5(7.6)$ \\
\hline I had a computer-related job & $1(1.5)$ \\
\hline I use a computer for work & $30(45.5)$ \\
\hline I used a computer for work & $9(13.6)$ \\
\hline I seldom use a computer for work & $14(21.2)$ \\
\hline I never use a computer for work & $7(10.6)$ \\
\hline
\end{tabular}

Table 4. Experience of using Computers in Daily Life

\begin{tabular}{l|l}
\hline Responses & $\begin{array}{l}\text { Freq. } \\
(\%)\end{array}$ \\
\hline \hline I use one often & $21(31.8)$ \\
\hline I use one sometimes & $26(39.4)$ \\
\hline I seldom use one & $14(21.2)$ \\
\hline I never use one & $5(7.6)$ \\
\hline
\end{tabular}

Table 5. Self-evaluation of using Computers

\begin{tabular}{l|l}
\hline Responses & $\begin{array}{l}\text { Freq. } \\
(\%)\end{array}$ \\
\hline \hline Quite skilled & $5(7.6)$ \\
\hline Capable & $21(31.8)$ \\
\hline Not very skilled & $30(45.5)$ \\
\hline Not skilled at all & $10(15.2)$ \\
\hline
\end{tabular}

Figure 1 shows results regarding interest in programming education. As the graphs for item 1 and 3 show, majority of the respondents are interested in programming education and welcome the introduction of programming education in elementary school. However, as the graphs for item 2 and 4 show, they are not familiar with the contents of education, meaning that they do not have enough information about programming education.

Figure 2 and 3 show responses to questions concerning attitudes toward programming education (Table 7) before and after workshops. Respondents were asked to choose a response from a five-point Likert scale ranging from 1 - I fully think so, to 5 - I do not think so at all. As concerns teaching programming education in elementary school (item 2 and 3), about $75 \%$ of respondents responded with 1 or 2 . They support teaching programming in elementary school. However, in response to "Everyone needs to know how to program" and "Programming should be part of the elementary school curriculum," more than half of the respondents chose "neutral," "I do not think so" or "I do not think so at all" before the workshops, but after the workshops, the number of respondents who gave these responses decreased. It seems that lack of enough information perhaps affected their attitudes, and that participation in the workshops promoted their understanding of programming.

Table 6. Questions Concerning Parents' Interests in Programming Education

\begin{tabular}{|l|}
\hline (1) Are you interested in programming education in elementary school? \\
\hline (2) Do you know what the new Course of Study (teaching guidelines issued by the Ministry of Education, Culture, \\
Sports, Science and Technology) for elementary schools stipulates regarding programming education? \\
\hline (3) Are you in favor of or opposed to programming education in elementary school? \\
\hline (4) Do you know what children currently learn concerning computers in elementary school? \\
\hline
\end{tabular}




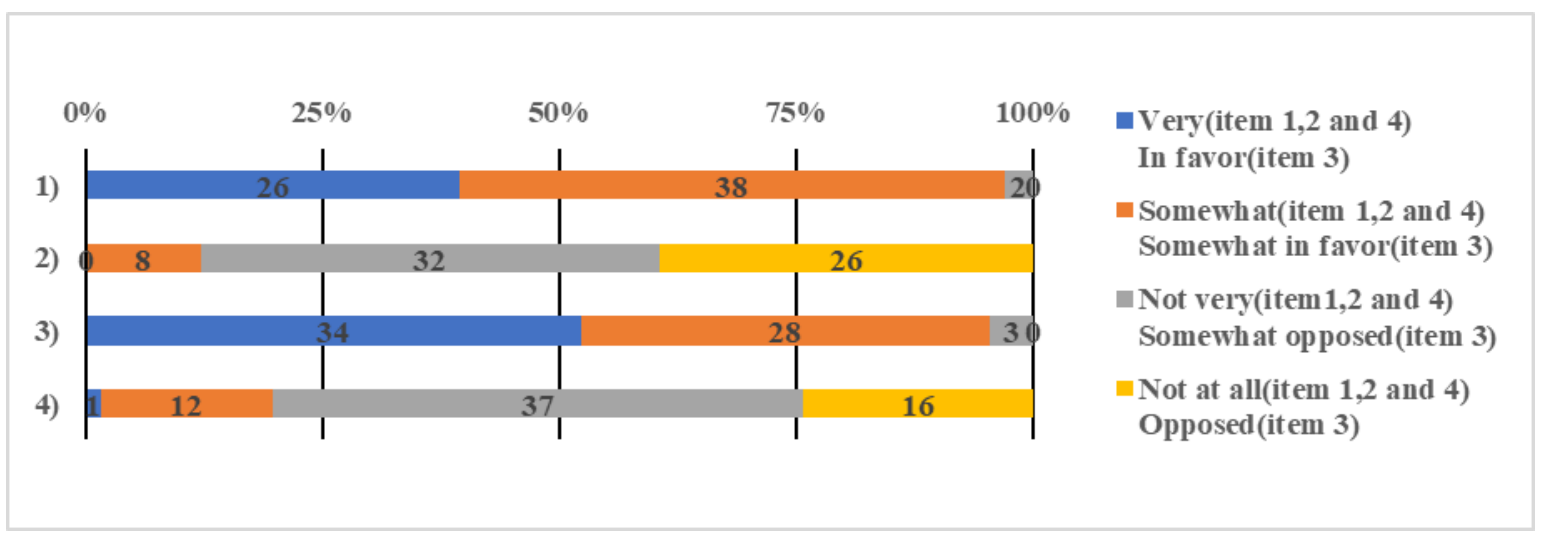

Figure 1. Responses to Questions Concerning Interests

Table 7. Questions Concerning Parents' Attitudes toward Programming Education

\begin{tabular}{l}
\hline Attitudes (How do you feel about programming being taught in school?) \\
(1) Everyone needs to know how to program. \\
(2) Programming should be taught in elementary school. \\
(3) Programming will be required in future societies, so it should be taught in elementary school. \\
(4) Elementary school is too early to learn programming. \\
(5) Programming should be part of the elementary school curriculum. \\
\hline (6) Programming will affect students other studies, so it should not be taught in elementary school. \\
\hline
\end{tabular}

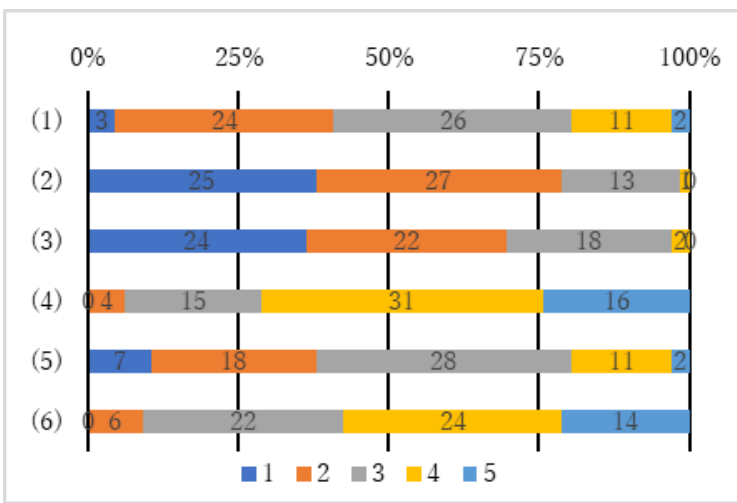

Figure 2. Responses to Questions Concerning Anxieties before Workshops

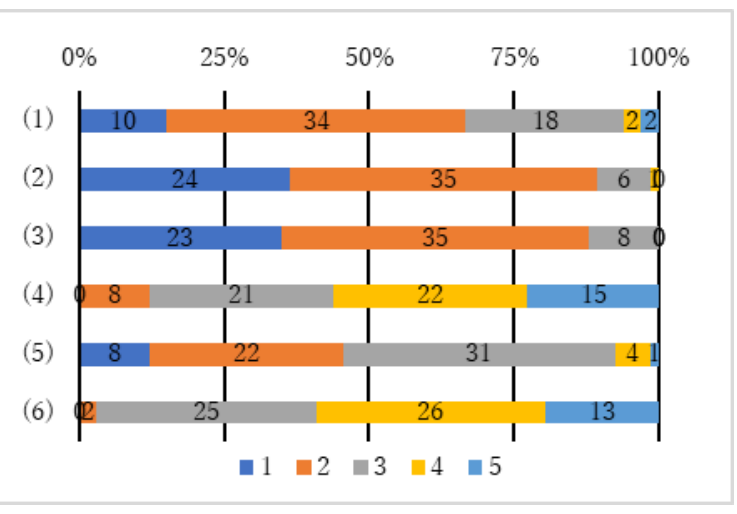

Figure 3. Responses to Questions Concerning Anxieties after Workshops

\subsection{Expectations and Anxieties about Programming Education}

Figure 4 shows results concerning expectations before workshops. Respondents were asked to choose a response from a five-point Likert scale ranging from 1 - I fully expect it, to 5 - I do not expect it at all. The graphs are in descending order of rate of respondents who chose response 1 or 2; that is, in order of expectation. Each alphabet located in the labels on the horizontal axis stands for categories mentioned in section 3.2.1. It suggests that respondents had high expectations of outcomes related to computers as well as knowledge of computers and ICT. On the other hand, concerning general skill, they expected that "Children will learn to think logically," but did not have much expectations for outcomes related to communication (item 12 and 22) and to collaboration (item 23). It seems to be easy for parents to associate programming with logical thinking skills. However, parents considered not to have much experience in programming cannot visualize the process of programming, so they do not expect communication and collaboration skills as outcomes. 
To explore differences in expectations before and after the workshop, a Wilcoxon signed-rank test was conducted. The results are shown in table 9 . The results indicate statistically significant differences for item $1,7,8,9,10,12,19,21,22$, and 23. Expectations for general skills increased. This was probably because experiences in workshops promoted understanding of programming and programming education.

Table 8. Questions Concerning Parents' Expectations and Anxieties

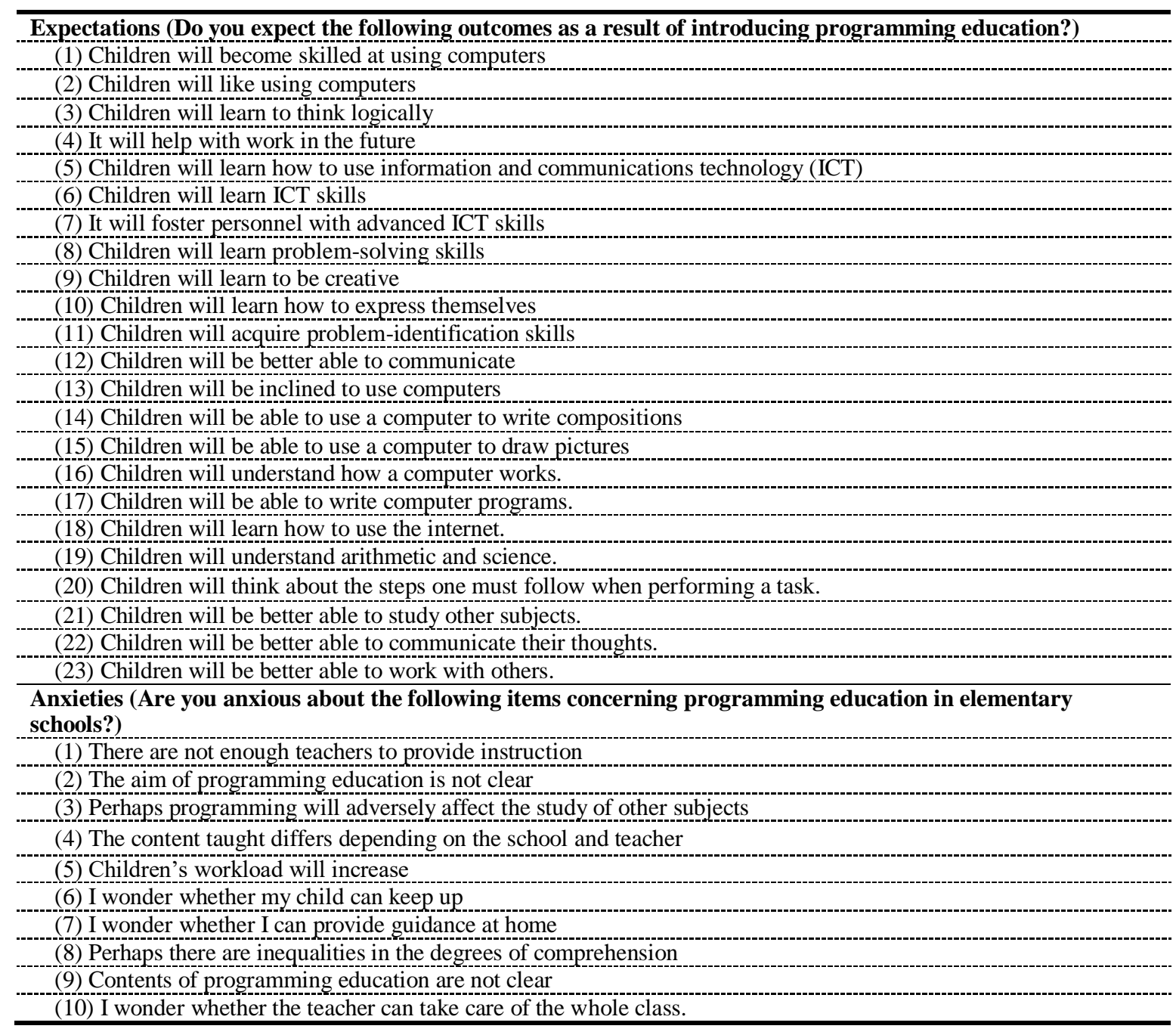

This tendency is shown in results concerning anxieties. Figure 5 and 6 show responses to questions concerning anxieties before and after workshops respectively. Respondents were asked to choose a response from a five-point Likert scale ranging from 1- I am very anxious, to 5 - I am not anxious at all. For item 9 which reads, "Contents of programming education are not clear," the number of respondents that chose response 1 or 2 decreased after the workshops. Statistically significant differences for item 9 were confirmed by the Wilcoxon signed-rank test $(\mathrm{p}=0.00<0.01)$. It is likely that their experiences in the workshops promoted their understanding of programming so that they were able to visualize the contents of programming education.

Results of the Wilcoxon signed-rank test indicate statistically significant differences for item 7 and 10 $(\mathrm{p}=0.001<0.01$ and $\mathrm{p}=0.025<0.05)$. The study suggests that participation in the workshop has an effect on decreasing parents' anxieties. 


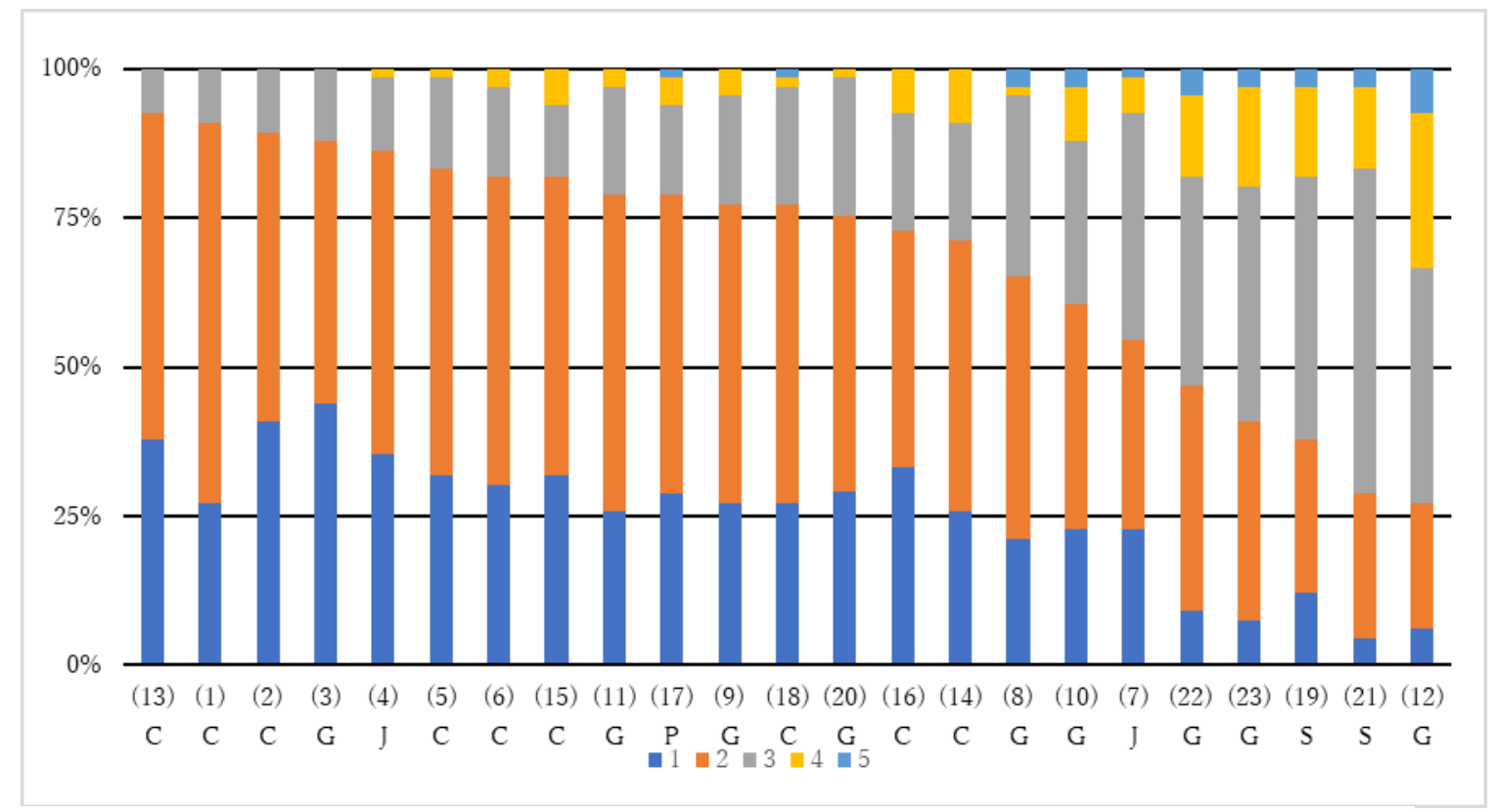

Figure 4. Responses to Questions Concerning Attitudes before Workshops

Table 9. Responses to Questions Concerning Attitudes before and after Workshops

\begin{tabular}{|c|c|c|c|c|c|c|c|c|c|c|c|}
\hline & \multicolumn{5}{|c|}{ Before } & \multicolumn{5}{|c|}{ After } & \multirow[b]{2}{*}{$p$} \\
\hline & 1 & 2 & 3 & 4 & 5 & 1 & 2 & 3 & 4 & 5 & \\
\hline (1) & $\overline{c 18}$ & 42 & $\overline{6} 6$ & $\overline{00}$ & $\bar{~} 0$ & 30 & 32 & 2 & 2 & $\bar{~} \overline{0}$ & "0.033* \\
\hline (2) & 27 & 32 & 7 & 0 & 0 & 29 & 31 & 6 & 0 & 0 & 0.532 \\
\hline (3) & 29 & 29 & 8 & 0 & 0 & 29 & 28 & 7 & 2 & 0 & 0.738 \\
\hline (4) & 23 & 33 & 8 & 1 & 0 & 28 & 25 & 12 & 1 & 0 & 1.000 \\
\hline (5) & 21 & 34 & 10 & 1 & 0 & 28 & 27 & 8 & 3 & 0 & 0.29 \\
\hline (6) & 20 & 34 & 10 & 2 & 0 & 28 & 28 & 7 & 3 & 0 & 0.079 \\
\hline (7) & 15 & 21 & 25 & 4 & 1 & 22 & 23 & 17 & 4 & 0 & $0.016^{*}$ \\
\hline (8) & 14 & 29 & 20 & 1 & 2 & 23 & 25 & 15 & 2 & 1 & $0.013^{*}$ \\
\hline (9) & 18 & 33 & 12 & 3 & 0 & 28 & 26 & 9 & 3 & 0 & $0.034^{*}$ \\
\hline (10) & 15 & 25 & 18 & 6 & 2 & 22 & 26 & 16 & 1 & 1 & $0.002^{*}$ \\
\hline (11) & 17 & 35 & 12 & 2 & 0 & 25 & 26 & 14 & 1 & 0 & 0.163 \\
\hline (12) & 4 & 14 & 26 & 17 & 5 & 10 & 18 & 26 & 7 & 5 & $0.000^{* *}$ \\
\hline (13) & 25 & 36 & 5 & 0 & 0 & 33 & 29 & 4 & 0 & 0 & 0.072 \\
\hline (14) & 17 & 30 & 13 & 6 & 0 & 15 & 27 & 19 & 5 & 0 & 0.402 \\
\hline (15) & 21 & 33 & 8 & 4 & 0 & 21 & 31 & 11 & 3 & 0 & 0.99 \\
\hline (16) & 22 & 26 & 13 & 5 & 0 & 25 & 26 & 12 & 3 & 0 & 0.163 \\
\hline (17) & 19 & 33 & 10 & 3 & 1 & 20 & 31 & 12 & 3 & 0 & 0.724 \\
\hline (18) & 18 & 33 & 13 & 1 & 1 & 21 & 30 & 11 & 3 & 0 & 0.519 \\
\hline (19) & 8 & 17 & 29 & 10 & 2 & 12 & 19 & 28 & 5 & 2 & $0.014^{*}$ \\
\hline (20) & 19 & 30 & 15 & 1 & 0 & 26 & 25 & 12 & 3 & 0 & 0.353 \\
\hline (21) & 3 & 16 & 36 & 9 & 2 & 15 & 13 & 28 & 6 & 4 & 0.023 \\
\hline (22) & 6 & 25 & 23 & 9 & 3 & 13 & 24 & 21 & 5 & 3 & $0.009^{* *}$ \\
\hline (23) & 5 & 22 & 26 & 11 & 2 & 10 & 24 & 21 & 8 & 3 & $0.028^{*}$ \\
\hline
\end{tabular}




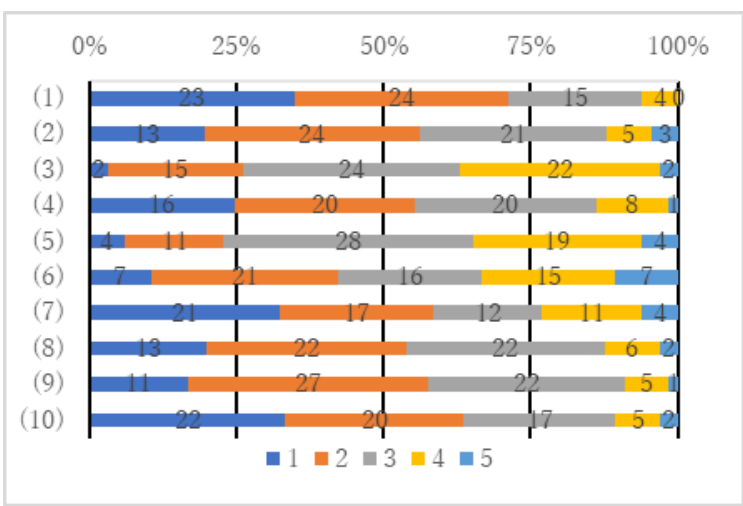

Figure 5. Responses to Questions Concerning Anxieties before Workshops

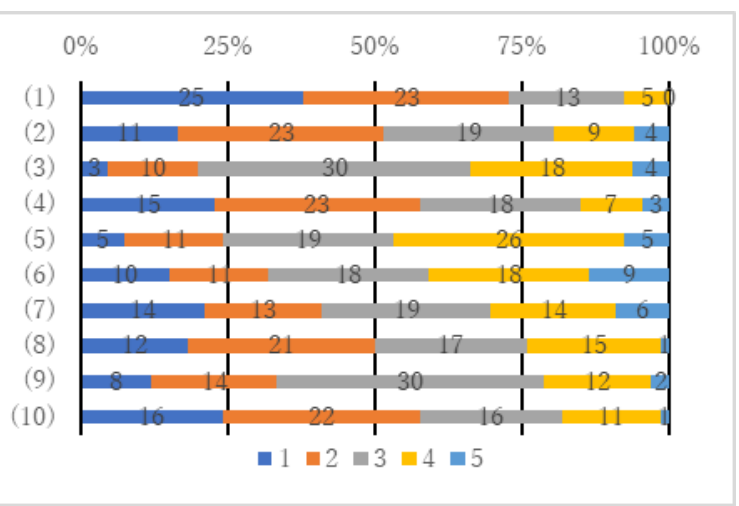

Figure 6. Responses to Questions Concerning Anxieties after Workshops

\subsection{Attitudes toward and Confidence in Supporting Children at Home}

The effects of participation in the workshop can be observed in changes in attitudes toward and confidence in supporting children's programming education at home. Figure 7, 8, and 9 show responses to three questions concerning supporting children at home (table 10). Concerning necessity of supplementary instruction, parents who answered "fully think so," or "somewhat think so" increased. Concerning involvement, parents who answered "will be actively involved" or "will be actively involved to a certain extent" increased. Concerning confidence in supporting children at home, parents who answered "I'm not confident at all" decreased. On the contrary, those who answered "I'm somewhat confident" increased. The results of the Wilcoxon signed-rank test indicated statistically significant differences among all of them $(p=0.003<0.01$, $p=0.000<0.001$ and $p=0.000<0.01$. Attitudes toward and confidence in supporting children at home improved as a result of participating in the workshop.

\section{Table 10. Questions Concerning Support at Home}

(1) Do you think supplementary instruction outside of school will be necessary for programming education?

(2) Do you think you will be involved in supplementary instruction for programming education at home?

(3) If you will be involved in supplementary instruction at home, how much confidence do you have in your involvement?

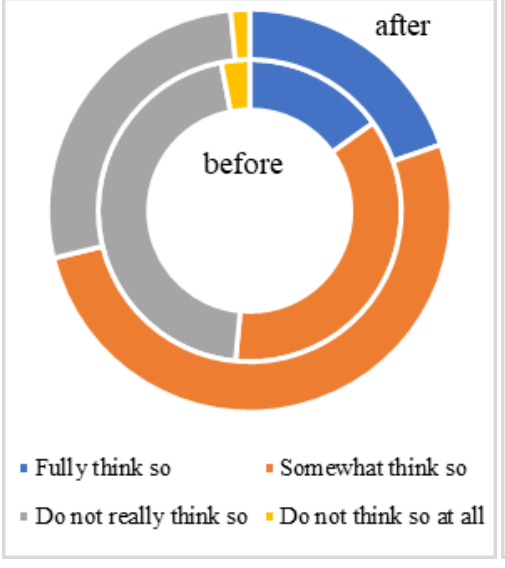

Figure 7. Views on the Necessity of Supplementary Instruction

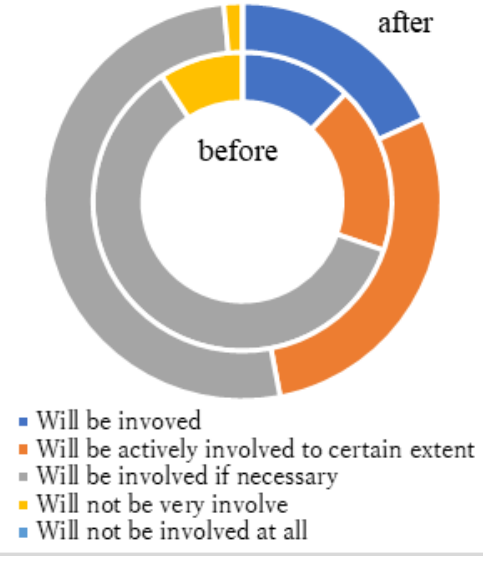

Figure 8. Involvement in Supplementary Instruction

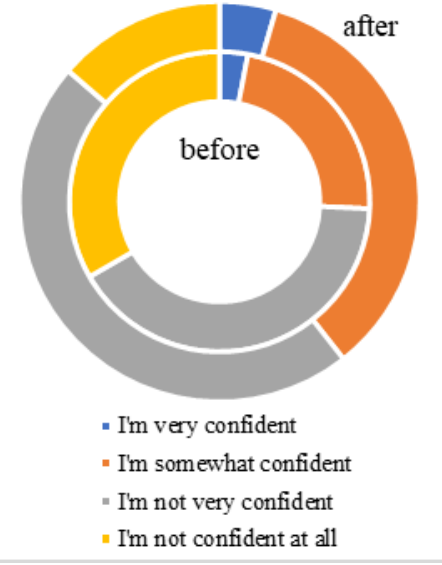

Figure 9. Confidence in Involvement in Supplementary Instruction 


\section{CONCLUSION}

This paper provides research findings from the results of a preliminary investigation into the influence of participation in a parent-children programming workshop on parents' concerns about programming education in elementary schools.

It is likely that experiences in workshops promote parents' understanding of programming so that they are able to visualize the contents of programming education. Moreover, attitudes toward and confidence in supporting children at home improved as a result of participation in the workshop.

However, the number of participants in this study was limited. It is necessary to carry out this survey with more participants and a detailed analysis.

\section{ACKNOWLEDGEMENT}

This work was supported by JSPS KAKENHI Grant Number JP18K02832.

\section{REFERENCES}

Barr, V., and Stephenson, C., 2011. Bringing computational thinking to K-12: What is involved and what is the role of the computer science education community? Acm Inroads, Vol. 2, No. 1, pp. 48-54.

Cuellar, F., Penaloza, C. and Kato, G., 2013, August. Robotics education initiative for parent-children interaction.In RO-MAN, 2013 IEEE (pp. 364-365). IEEE.

Feng, H.C., Lin, C.H. and Liu, E.Z.F., 2011. Parents' perceptions of educational programmable bricks for kids. BritishJournal of Educational Technology, 42(2), pp.E30-E33.

Grover, S., and Pea, R., 2013. Computational thinking in K-12: A review of the state of the field. Educational Researcher, Vol. 42, No. 1, pp. 38-43.

Hart, M. L., 2010, Making contact with the forgotten K-12 influence: Are you smarter than YOUR 5th grader? Proceedings of the 41st ACM technical symposium on Computer science education, Wisconsin, USA, pp. 254-258.

Lin, C.H., Liu, E.Z.F. and Huang, Y.Y., 2012. Exploring parents' perceptions towards educational robots: Gender and socio-economic differences. British Journal of Educational Technology, 43(1).

Lin, J. M.-C., and Liu, S.-F., 2012. An investigation into parent-child collaboration in learning computer programming. Educational Technology \& Society, Vol.15, No.1, pp162-173.

Lye, S. Y., and Koh, J. H. L., 2014, Review on teaching and learning of computational thinking through programming: What is next for K-12? Computers in Human Behavior, Vol. 41, pp. 51-61.

Makino, M., 2008. Parental perception of English activities at elementary schools - focusing on expectation and involvement-, Research Institute for Communication, Kansai University of International Studies, Studies on Communication, 6, 61-73 (in Japanese).

Morita, A., 2011. Data analysis of parents' involvement in primary school English language education, Waseda review of Education, 25, 1, 163 - 172 (in Japanese).

Papert, S., 1993. Mindstorms: Children, Computers, and Powerful Ideas, 2nd ed, Basic Books, New York.

Resnick, M., 2012, Mother's day, warrioir cats, and digital fuluency: Stories from the Scratch online comunity, Procceedings of the Constructionism 2012 conference, Athens, Greece, pp1-7.

Roque, R., Lin, K. and Liuzzi, R., 2016. "I'm Not Just a Mom": Parents Developing Multiple Roles in Creative Computing. Singapore: International Society of the Learning Sciences.

Wing, J.M. 2006. Computational Thinking, Communications of the ACM, Vol. 49, No. 3, pp. 33-35.

Yamamot, T., Hongou, T., Motomura, T., and Nagai, K., 2016, Consideration of educatinal significance of programming education in elementary secondary education, Kyouiku Joho Kenkyu [Study on Educational Information (translated by author)], 32, 2, pp3-11 (in Japanese). 